\title{
EFFECT OF SUDARSHAN KRIYA ON FUNCTIONAL CAPACITY, QUALITY OF LIFE AND STRESS LEVELS IN PATIENTS WITH TYPE 2 DIABETES: A PROSPECTIVE EXPERIMENTAL STUDY
}

\section{Donna Adhav Gaikwad ${ }^{* 1}$, Rachna Arora ${ }^{2}$, Hutoxi Writer ${ }^{3}$.}

${ }^{*}$ Post Graduate Student, Physiotherapy, Topiwala National Medical College and B.Y.L Nair, Hospital, Dr. A.L.Nair Road, Mumbai, India.

${ }^{2}$ Assistant Professor, Physiotherapy, Topiwala National Medical College and B.Y.L Nair, Hospital, Dr. A.L.Nair Road, Mumbai, India.

${ }^{3}$ Head Of Physiotherapy Department, Physiotherapy, Topiwala National Medical College and B.Y.L Nair, Hospital, Dr. A.L. Nair Road, Mumbai, India.

\section{ABSTRACT}

Background: Type 2 diabetes mellitus describes a metabolic disorder of multiple etiologies characterized by chronic hyperglycemia resulting from defects in insulin secretion or insulin action or both. Diabetic management consists of a combination of diet, exercise, and weight loss. Sudarshan Kriya yoga use specific rhythms of the breath to eliminate stress, support the various organs and systems and restore peace of mind but no scientific study has been done to assess the efficacy. Hence the study was done to establish a scientific basis of sudarshan kriya yoga as an adjunct to conventional medical management on functional capacity, Quality of life and stress levels in type 2 diabetic subjects.

Materials and Methods: 60 subjects were enrolled and according to their latest glycemic index (HbA1c), stratified into 2 groups ( 30 in each group) - with fair to good control $(<8)$ and with poor control $(>8)$. Block randomization method using a block of four was used for random allocation of subjects to experimental (sudarshankriya yoga) and control groups (breathing exercises). Baseline assessment of Functional Capacity, Quality of life and stress levels was done using 6 Minute Walk Test, SF-36 and Hamilton depression rating Scale respectively. The pre post measurements of outcome measures were analysed.

Results: Following 4 weeks of Sudarshan kriya Yoga and Breathing exercises, there was a statistically significant increase in 6 MWD, SF 36 scores in all domains and reduction in \% Heart Rate rise and Hamilton Depression Rating scores and no statistically significant reduction in Basal Heart Rate. However the increase was statistically more significant in the experimental group as compared to the control group.

Conclusion: Sudarshan Kriya yoga has an effect on functional capacity, quality of life and stress levels in subjects with Type 2 Diabetes Mellitus. As Sudarshan Kriya Yoga shows improvement not only in the autonomic function but also shows a reduction in stress levels, it should be incorporated as an adjunct in the management of these subjects.

KEY WORDS: Diabetes Mellitus, Sudarshan Kriya Yoga, SF 36.

Address for correspondence: Dr. Donna Adhav Gaikwad, Post Graduate Student, Physiotherapy, Topiwala National Medical College and B.Y.L Nair Hospital, Dr. A.L.Nair Road, Mumbai 400008.

E-Mail: donnagaikwad@gmail.com

Access this Article online

Quick Response code

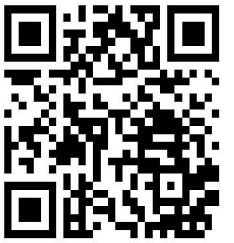

DOI: $10.16965 /$ ijpr.2019.115

Journal Information

International Journal of Physiotherapy and Research

ICV for 2016
86.93

ISSN (E) 2321-1822 | ISSN (P) 2321-8975

https://www.ijmhr.org/ijpr.html DOI-Prefix: https://dx.doi.org/10.16965/ijpr

\section{Article Information}

Received: 26 Feb 2019

Peer Review: 28 Feb 2019

Revised: None
Accepted: 01 Apr 2019

Published (O): 20 Apr 2019

Published (P): 11 Jun 2019

\section{BACKGROUND}

Diabetes represents a spectrum of metabolic disorders, which has become a major health challenge worldwide.Of all the non-communi 
cable diseases, diabetes and cardiovascular diseases lead the list. Diabetes is pandemic in both developed and developing countries [1].

India currently has around $\mathbf{4 0}$ million cases of T2DM (Type 2 Diabetes Mellitus) and these numbers are projected to increase to 87 million by the year 2030 [2]. Anticipating an epidemic like increase in the number of diabetic patients, India has been christened as the 'diabetic capital of the world [3]. The prevalence of T2DM has risen from $1.2 \%$ to $11 \%$ over last three decades [4].

One of the most comprehensive breathing techniques derived from the Yogic Science of Breath is Sudarshan Kriya yoga. Su means proper, darshan means vision and kriya means purifying practice and the Sudarshan Kriya is exactly that - a purifying practice. It is traditionally understood to use specific rhythms of the breath to eliminate stress, support the various organs and systems within the body, transform overpowering emotions and restore peace of mind. Studies by Gerbarg and Brown have shown that Sudarshan Kriya significantly reduce levels of stress (reduce cortisol - the "stress" hormone), benefit the immune system, reduce cholesterol, relieve anxiety and depression, increase antioxidant protection, enhance brain function (increased mental focus, calmness and recovery from stressful stimuli), enhance health, well-being and peace of mind and improves pulmonary function and gas exchange [4]. However, these studies did not include a control group and were for a very short duration.

AIM: To assess the effects of Sudarshan kriyaYoga on functional capacity, Quality of life and stress levels in subjects with Type 2 Diabetes Mellitus.

\section{OBJECTIVES:}

1. To assess functional capacity, quality of life and stress levels pre \& post intervention in Experimental group performing Sudarshan Kriya Yoga..

2. To assess functional capacity, quality of life and stress levels pre \& post intervention in Control group performing Breathing Exercises.

3. To compare the change in functional capacity, quality of life and stress levels pre and post intervention in both groups.

\section{MATERIALS AND METHODS}

Research design: Randomised controlled trail. Population: Subjects with type 2 diabetes. Sample size: 60 subjects (30 in each group)

Type of sampling: Stratified sampling according to glycaemic index with 30 subjects having glycaemic index $<8$ and 30 subjects having glycaemic index $>8$. Block randomization (block of 4) within each strata was done to assign subjects in experimental and control group.

Source of sampling: Diabetic Out Patient Department of tertiary health care hospital. Place of study: Physiotherapy Dept of tertiary health care hospital. Duration of study: $2012-2015$

Inclusion criteria: Subjects with type 2 diabetes diagnosed for 2 or more years on stable dose of medications. Age group $-30-60$ years.

Exclusion criteria: Subjects with recently diagnosed diabetes ( $<2$ years). Subjects with any recent hemodynamic, pulmonary \& cardiac complications in previous 3 months. Recent major illness in previous 1 month. Recent cardiac or pulmonary surgery. Subjects diagnosed and under treatment for depression. Unwillingness to participate in the study.

Material used: B.P Apparatus, stethoscope, cones for 6 Minute Walk Test, Measuring Tape.

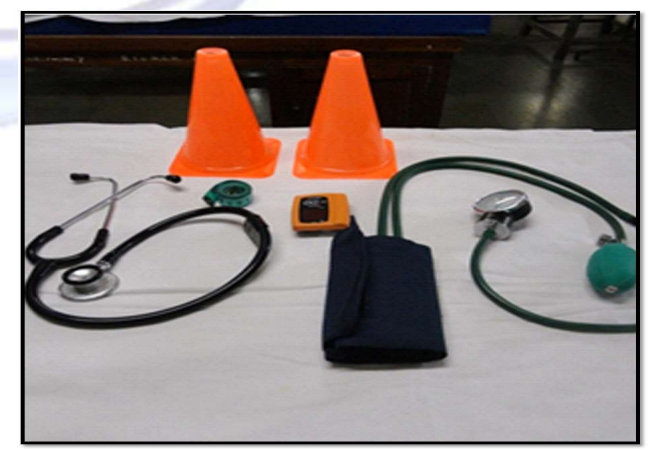

\section{OUTCOME MEASURES:}

Primary Outcome Measures: 6 minute walk test (6MWT) - in meters, Quality of life (QOL) SF-36 questionnaire - 9 domains, each scored out of 100, Hamilton depression rating scale (HAMD) - Total score 54.

Secondary Outcome measures: Basal Heart Rate (HR), Basal Systolic Blood Pressure (BP), $\%$ Rise HR (calculated as Percentage of HRmax) in 6 Minute Walk Test

HRmax $=220-$ Age 
Rise in $H R=H R_{\text {peak }}-H R_{\text {basal }}$

$\%$ Rise $=\underline{\text { Rise in HR }} \times 100$

HR max

The approval for the study was taken from the local institution Ethics Committee and MAHARASHTRA UNIVERSITY OF HEALTH SCIENCES research board. Block randomization method using a block of four was used for random allocation of subjects to experimental (sudarshankriya yoga) and control groups (breathing exercises). This randomization was done separately for group with fair to good glycemic control $(\mathrm{HbA} 1 \mathrm{c}<8)$ and group with poor glycemic control ( $\mathrm{HbA1c}>8)$. It was done prior to the commencement of the study by an independent person and sealed in separate, opaque, numbered envelops (each containing allocation for 4 subjects).

Schematic Representation of methodology

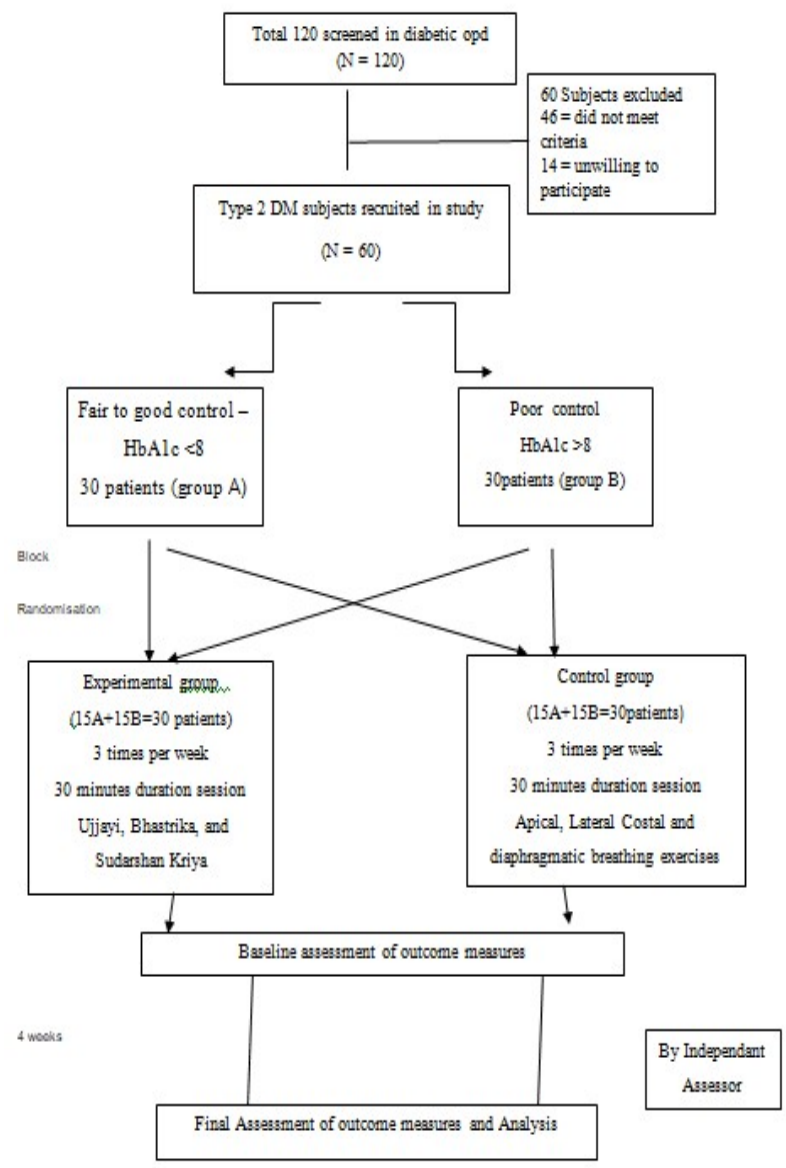

Experimental group: The experimental group received sudarshankriya yoga thrice a week for a period of 4 weeks. The duration of a single session was 30 minutes.

Ujjayi Pranayam: slow breathing $(2-4$ cycles per minute) against airway resistance main tained throughout inspiration and expiration by slight contraction of laryngeal muscles \& partial closure of glottis. Each breath cycle consisted of 4 phases - inspiration, end inspiration breath holding, expiration, end expiration breath holding.

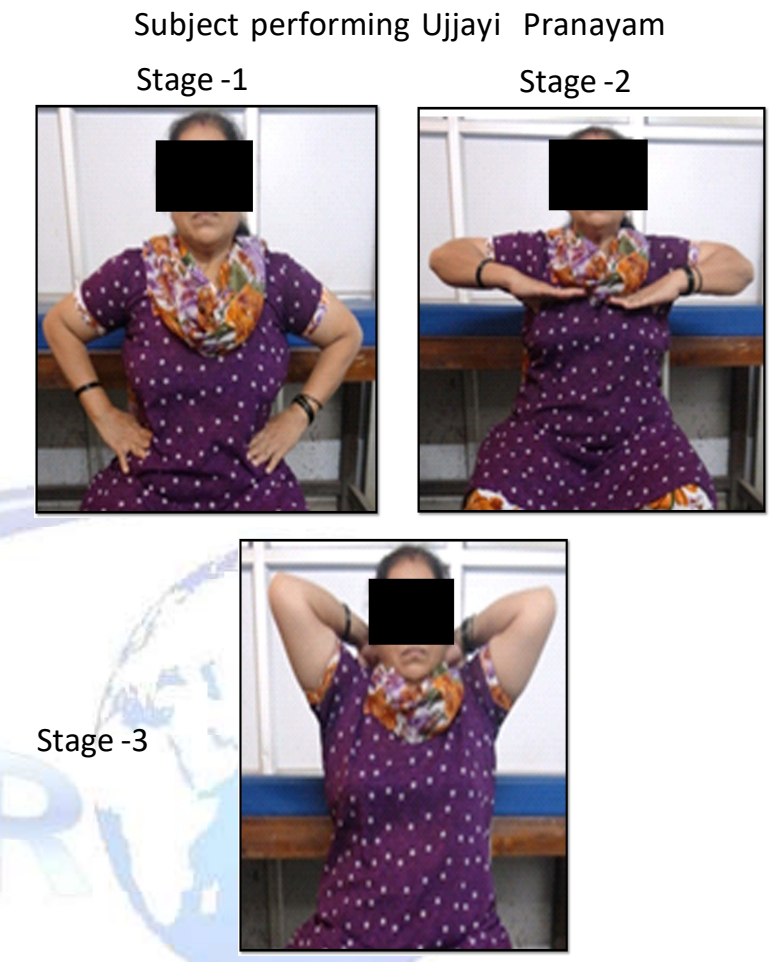

Bhastrika: The breath is forcefully inhaled \& then exhaled using strong abdominal contraction. 3 rounds of bhastrika with $15-20$ breath cycles each are followed by 20 seconds of rest.

Subject performing Bhastrika Pranayam
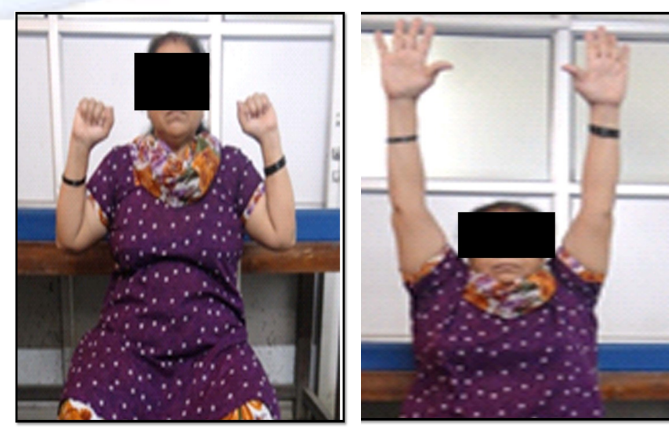

Subject performing Sudarshan Kriya Yoga

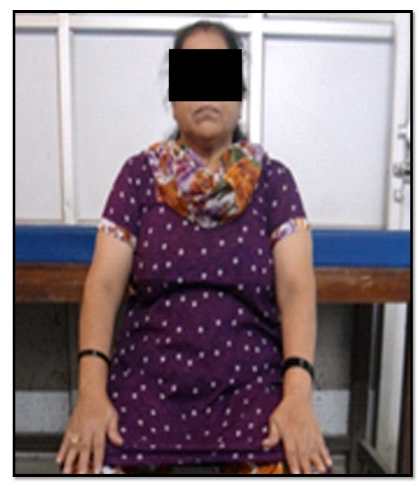


Sudarshan kriya yoga: Three different rates of breathing was used- slow (8-14cpm), medium (30 cpm) and rapid(150-180cpm) which formed one set. Three sets of 20 slow, 40 medium and 40 rapid cycles was performed.

Control Group: The control group received breathing exercise thrice a week for 4 weeks for 30 minutes. It consisted of apical, Lateral Costal and diaphragmatic breathing exercises with pursed lip breathing exercises.

Subject performing Breathing Exercises

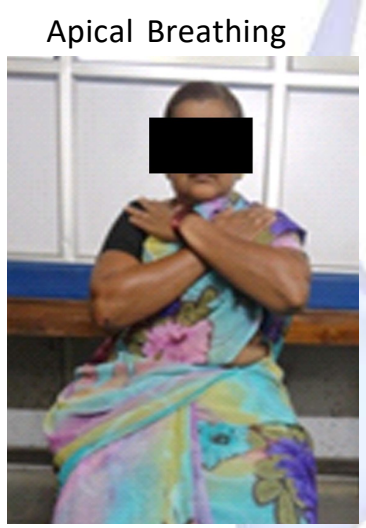

Lateral Costal Breathing

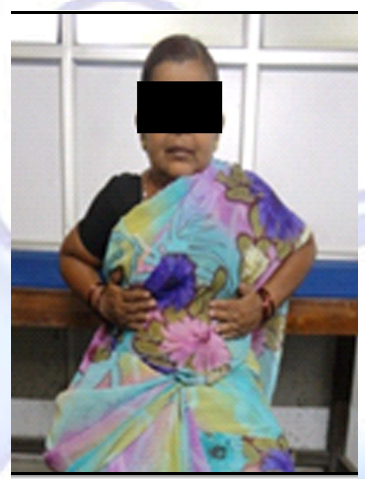

Diaphragmatic Breathing

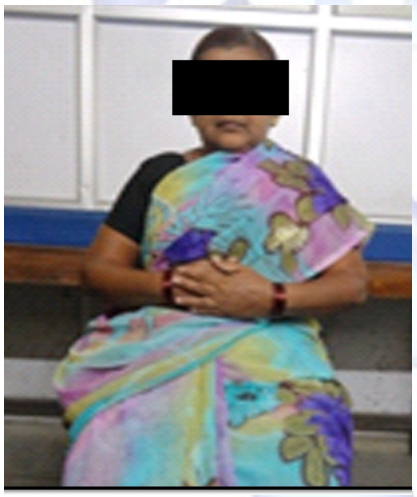

In both groups, the subjects were monitored for heart rate and Blood Pressure variations during the procedure as a safety precaution.

All the subjects completed the study, there was no loss to follow-up. The data was collected for analysis.

Data analysis: The data was analyzed using SPSS 16 software.The data was tested for normality with the Shapiro Wilk test. Paired and unpaired ' $\mathrm{t}$ ' Test was used to analyse data passing normality and Wilcoxin Sign rank test and Mann Whitney $U$ test was used to analyse data not passing normality. Both groups were compared at baseline for homogeneity. Within group analysis and comparison of differences between the groups were also analysed. There was difference in 6 Minute Walk Distance (6 MWD) in both experimental and control groups at baseline, hence ANCOVA test was done to nullify the effect of covariance i.e.pre-intervention 6MWD on post training difference in 6MWD. Effect Size using Partial Eta squared was found for 6 MWD.

\section{RESULT}

At baseline, both the groups were homogeneous with respect to Age, $\mathrm{HbA} 1 \mathrm{c}$ and duration of diabetes and with the exception of 6MWD, there was no statistically significant difference in all other outcome measures i.e. Basal HR, \% HR rise, SF 36 and HAMD. (Table 1)

Table 1: Descriptive statistics in both groups at baseline.

\begin{tabular}{|c|c|c|c|c|}
\hline $\begin{array}{l}\text { Outcome } \\
\text { Measures }\end{array}$ & Experimental group & Control group & Test & $P$ value \\
\hline $6 \mathrm{MWD}$ & $271.50 \pm 26.52 \mathrm{mts}$ & $247.00 \pm 31.45 \mathrm{mts}$ & Mann Whitney & $p=0.003$ \\
\hline$\%$ HR RISE & $11.40 \pm 4.73$ & $11.09 \pm 3.04$ & Mann Whitney & $\mathrm{p}=0.982$ \\
\hline $\mathrm{SF}-36 \mathrm{PF}$ & $65(60.8-69.1)$ & $75(67.6-75.60)$ & \multirow{8}{*}{ Mann Whitney } & \\
\hline $\mathrm{PH}$ & $1(65.9-87.33)$ & $1(67.1-86.14)$ & & \\
\hline 8 & $1(66.2-87.44)$ & $50(57.7-75.6)$ & & \\
\hline 20 & $65(60.3-70.2)$ & $67.5(59.8-69.1)$ & & \\
\hline EWB & $66.5(60.26-69.8)$ & $65(63.1-69.8)$ & & \\
\hline SF & $75(73.39-78.93)$ & $67.5(67.9-74.7)$ & & \\
\hline PAIN & $75(67.6-76.03)$ & $70(68-74.3)$ & & \\
\hline GH & $65(61.05-69.94)$ & $65(62.92-70.41)$ & & \\
\hline HAMD & $9.00(8.10-10.16)$ & $7(6.45-7.48)$ & Mann Whitney & $p=0.071$ \\
\hline
\end{tabular}

6MWD - 6 Minute Walk Distance, HR - Heart Rate, PF Physical Function, PH - Physical Health, EP - Emotional Problem, EF - Energy Fatigue, EWB - Emotional Well Being, SF - Social Function, GH - General Health, HAMD Hamilton Depression Rating Scale.

Sudarshan kriya Yoga Group showed a significant increase in $6 \mathrm{MWD}$, SF 36 scores in all domains, decrease in \% HR rise, decrease in HAMD scores and no significant decrease in Basal HR after 4 weeks. (Table 2)

The Breathing exercises Group showed a significant increase in 6 MWD, SF 36 scores in all domains, decrease in \% HR rise, HAMD scores and no significant reduction in Basal HR after 4 weeks. (Table 2)

The increase in 6 MWD and SF 36 score in all domains as well as reduction in \% HR rise and HAMD score was statistically more significant in the experimental group as compared to the control groupwith the estimated mean difference in $6 \mathrm{MWD}$ of 60 meters (SE 3.78, 95\% Cl, $52.38-67.618$ ) in the Sudarshan Kriya Group and 22.34 meters (SE 3.266, 95\% Cl, 15.766 - 28.922) in the Breathing Exercise Group.(Table 3)

The Effect Size of the increase in 6 MWD in the experimental group was found to be large $\left(\check{z}_{p}{ }^{2}=\right.$ $0.558)$. 
Table 2: Pre and Post intervention comparison be tween the groups.

Table 3: Comparison of outcome measures between the groups.

\begin{tabular}{|c|c|c|c|c|c|c|c|}
\hline \multirow{2}{*}{$\begin{array}{c}\text { Outcome } \\
\text { measures }\end{array}$} & \multicolumn{3}{|c|}{ Experimental Group } & \multicolumn{3}{c|}{ Control group } & \multirow{2}{*}{ Test } \\
\cline { 2 - 8 } & Pre & Post & P value & Pre & Post & P value & \\
\hline 6MWD & $.22 .71+2.65+222.65$ & $3.29+393.29+3$ & 0 & $2.47+3.14$ & $2.70+22.70+3.73$ & 0 & \\
\hline \%HR Rise & $11.4+4.73$ & $6.19+1.53$ & 0 & $11.09+3.03$ & $12.82+1.6$ & 0.018 \\
\hline SF-36 PF & $65(60.8-69.1)$ & $80(78.4-83.5)$ & 0 & $75(67.6-75)$ & $77.5(74.2-80.4)$ & 0 \\
\hline PH & $1(66-87.3)$ & $1(89-1)$ & 0.001 & $1(67-86.1)$ & $1(72.5-91)$ & 0.083 \\
\hline EP & $1(66-87.4)$ & $1(89.3-1)$ & 0.001 & $50(57.7-75.6)$ & $1(89.3-1)$ & 0 & \multirow{2}{*}{ WILCOXON } \\
\hline EF & $65(60.3-70.2)$ & $75(74.7-70.2)$ & 0 & $67.5(60-69)$ & $75(68.3-75)$ & 0 & SIGNED RANK \\
\hline EWB & $66.6(60.2-68.9)$ & $82(78.2-84.2)$ & 0 & $65(63-70)$ & $70(69.6-77)$ & 0 & \multirow{2}{\text{TEST}}{} \\
\hline SF & $75(73.3-78.9)$ & $88(84.8-88.7)$ & 0 & $67.5(67.9-74.7)$ & $75(73-80.8)$ & 0 \\
\hline PAIN & $75(67.6-76)$ & $80(80-85.5)$ & 0 & $70(68-74.3)$ & $77.5(73.1-79)$ & 0 \\
\hline GH & $65(61-70)$ & $80(76-83)$ & 0 & $65(63-70.4)$ & $72.5(68.2-74.7)$ & 0 \\
\hline HAMD & $9(8.1-10.1)$ & $6(5.7-6.6)$ & 0 & $8(7.2-8.79)$ & $7(74.2-80.40$ & 0 & \\
\hline
\end{tabular}

\begin{tabular}{|c|c|c|c|c|}
\hline Outcome measures & Experimental group & Control group & Test & $P$ value \\
\hline $6 \mathrm{MWD}$ & $57.5 \pm 1.72 \mathrm{mts}$ & $23 \pm 1.51 \mathrm{mts}$ & Mann Whitney & $p=0.000$ \\
\hline \% HR RISE & -0.78 & $1.74 \pm 1.68$ & Mann Whitney & $p=0.000$ \\
\hline$S F-36-P F$ & $15(13-18.8)$ & $5(4.13-7.19)$ & \multirow{8}{*}{ Mann Whitney } & $p=0.000$ \\
\hline $\mathrm{PH}$ & $0(9.18-27.48)$ & $0(-6.9-10.6)$ & & $p=0.015$ \\
\hline EP & $0(9.09-27.24)$ & $50(18.92-37.7)$ & & $p=0.094$ \\
\hline $\mathrm{EF}$ & $12.5(11.06-15)$ & $5(5.22-9.1)$ & & $p=0.000$ \\
\hline EWB & $17(15-18.32)$ & $5(5.32-8.34)$ & & $p=0.000$ \\
\hline SF & $12(8.7-12.47)$ & $5(4.2-7.1)$ & & $p=0.000$ \\
\hline PAIN & $10(8.8-12.7)$ & $5(3.2-6.7)$ & & $p=0.000$ \\
\hline GH & $15(12.08-16.25)$ & $5(3.17-6.49)$ & & $p=0.000$ \\
\hline HAMD & $-3(-3.74--2.1)$ & $-1(-1.43--0.63)$ & Mann Whitney & $p=0.000$ \\
\hline
\end{tabular}

\section{DISCUSSION}

The aim of this study is to assess the effects of Sudarshan Kriya yoga on functional capacity using six minute walk test, quality of life using SF 36 and stress levels using Hamilton depression rating scale (HAMD) in subjects with Type 2 Diabetes. Both groups received an exercise program of 4 weeks duration. The experimental group received sudarshankriya yoga and control group received breathing exercise (diaphragmatic breathing, segmental breathing and thoracic expansion exercises).

With the exception of 6MWD, there was no variability in all the outcome measures (Basal HR, Percentage HR rise, SF 36 and HAMD scores) in both the experimental and control groups at baseline.

Following 4 weeks of sudarshan kriya, there was an increase in functional capacity as seen by increase in $6 \mathrm{MWD}$, an improved cardiac function as seen by reduction in percentage $H R$ rise during $6 \mathrm{MWD}$. Furthermore, there was an improvement in Quality of life in all domains of SF 36 , and a reduction in stress levels as seen in a reduction in HAMD scores. However, there was no statistically significant reduction in Basal HR. Following 4 weeks of breathing exercises, there was an improvement in functional capacity, as seen by an increase in 6 MWD, improved cardiac function as seen by reduction in percentage HR rise during 6 MWT. Furthermore, there was an improvement in Quality of life as seen in, in all domains of SF 36, and a reduction in stress levels as seen in a reduction in HAMD scores. However, there was no statistically significant reduction in Basal HR. But the result shows that the increase in $6 M W D$, reduction in percent HR rise and HAMD score was more in the experimental group as compared to the control group which was statistically significant and increase in all domains of SF 36 was more in the experimental group as compared to the control group which was statistically significant. $(p=0.000)$. Also a statistically significant effect of pre test 6MWD [p=0.002] on the difference in 6 MWD in both groups and the estimated Mean and Standard Error of difference in 6 MWD in both groups after nullifying the 
effect of pre test variance in 6 MWD was found to be 60 metersin the experimental group and 22.72 meters in the control group.

Thus there is a statistically significant improvement in functional capacity, Quality of life and reduction in stress levels $(p=0.000)$ in the experimental group practicing Sudarshan Kriya as compared to the Control group practicing breathing exercises

Studies done by Kaushik Halder [5], 'AnjumSayyed [6], Vedamurthachar [7], Bharshankar [8], VivekaJyotsna [9], P.Narang [10] showed similar results.

Teresita corvera et al (2008) studied that diabetes mellitus reduces exercise capacity and heart rate variability [11]. James sharman et al (2005) states that decrease in the exercise capacity in type 2 diabetes mellitus is due to poor diabetic control, left ventricular dysfunction and impaired heart rate recovery [12].

In the present study, there was a significant reduction in the \% heart rate rise post sudarshan kriya training as suggested by Bharshankar. It may be due to fluctuations of blood pressure and increase in the normal respiratory sinus arrhythmia during the kriya. Stimulation of the vagal efferent neurons leads to a parasympathetic reduction in heart rate, baroreflex sensitivity and improved heart rate variability but has no change in basal systolic and diastolic blood pressure [8]. A study by Dipak Chauhan showed that SudarshanKriya and Bhastrika Pranayama were effective in bringing about significant improvement in the vital capacity with some improvement in endurance capacity [13]

Study done by Viveka P. Jyotsna et al showed significant improvement in the QOL and glycemic control in the group practicing the comprehensive yogic breathing as compared with the control group following standard treatment [14].

Kjellgren A [15], Brown et al [16], B.N.Gangadhar[17], sameer zope [18] suggest that participants in the SKY decreased anxiety, depression and stress, and increased their degree of optimism.

In the control group receiving 4 weeks of breathing exercise there was a statistically significant difference functional capacity, quality of life and stress levels. Study done by Kulur et al [19], Kaushik et al [20], Whitmore [21], Dr. LabibaAbd El-kader [22], C.K.Peng [23], Daniele Martarelli et al [24] support the above findings.

Kullur et al explained that the improvement in heart rate may be due to the direct effect of breathing exercise on the autonomic nervous system controlling the heart [19]. Kaushik et al added that slow, rhythmic breathing increases the parasympathetic tone causing a fall in systolic blood pressure, diastolic blood pressure, and heart rate [20]. This may be the possible reason for reduction in the \% rise in heart rate post breathing exercise during 6MWD. Whitmore concluded that breathing improves antioxidant defenses and decrease oxidative stress [21].

According to Richard Brown, Ujjayi breathing increases parasympathetic tone, respiratory sinus arrhythmia (RSA) and heart rate variability (HRV) and decreases chemoreflex sensitivity with improved arterial baroreflex sensitivity, oxygenation and exercise and stress tolerance [25]. During Bhastrika, activation of autonomic sympathetic leads to increased cardiac output and renal blood flow [26]. Telles, et al (1995) showed decreased metabolism and heart rate and increased peripheral vascular resistance on mentally chanting OM [27]. Sudarshan kriya yoga consists of cyclical breathing of three different rhythms of different lengths and repetitions.The effects of slow cycles of sudarshankriya are similar to Ujjayi and the medium and rapid cycles of sudarshankriya like Bhastrika, may stimulate the vagus nerve and activate thalamic oscillators.

Deep breathing is relaxing and increases parasympathetic tone, improves cardiovascular and respiratory functions, physical and mental health and decreases the sympathetic activity $[28,29]$ Deep breathing also increases blood and oxygen flow to the brain to function in its maximal state, improves heart health, energy levels and helps the body eliminate toxins, as well as reduces stress [30].

This study showed that sudarshankriya yoga increased the functional capacity with decrease in percent heart rate rise during 6MWD. This suggests better cardiac efficiency probably due to improvement in cardiac autonomic function. 
However, there was no change in resting heart rate and blood pressure response. The associated improvement in quality of life and reduction in stress levels are due to the mental effects of sudarshankriya and can also contribute to improved functional capacity, improved cognitive performance, better tissue perfusion, glucose metabolism and increased immune system. It is well documented that these physiological changes are associated with optimal human performance [31].

\section{CONCLUSION}

Sudarshan Kriya yoga has an effect on functional capacity, quality of life and stress levels in subjects with Type 2 Diabetes.

\section{ABBREVIATIONS}

\section{T2DM- Type 2 Diabetes Mellitus}

SKY - Sudarshan kriya yoga

QOL - Quality of life

HR - Heart Rate

BP - Blood Pressure

\section{ACKNOWLEDGEMENTS}

I owe my profound gratitude to our project guide Dr. Mrs. Rachna Arora, who took keen interest in the project work and guided all along, till the completion of project extend our sincere regards to all the non-teaching staff of department for their timely support.work by providing all the necessary information. I am thankful to and fortunate enough to get constant encouragement, support and guidance from Head Of Department of Topiwala National Medical College, BYL Nair Hospital Physiotherapy Department Dr. Hutoxi Writer and Head Of Department of Endocrinology Department Dr. Prema for helping me in successfully completing project work. I respect and thank Ms. Brooma (Art Of Living co-ordinator, Kalyan west) for giving me an opportunity to do the project work in Sudarshan Kriya Pranayam and providing all support and guidance which made me complete the project on time.

\section{Conflicts of interest: None}

\section{REFERENCES}

[1]. Ahsana Shah and Mohammad Afzal, Prevalence of diabetes and hypertension and association with various risk factors among different Muslim populations of Manipur, India Journal of Diabetes \& Metabolic Disorders 2013.

[2]. Hasan I, Khatoon S: Prevalence of diabetes mellitus and obesity among population of Sultanpurkunhari and its surrounding area, Haridwar Uttarakhand. Indian Journal of Diabetes 2012;3:226-229.
[3]. Joshi AR, Pranita A, Phadke AV: Diabesity: curse of development. International Journal of Medical Update 2012;7:77-78.

[4]. Patricia L. Gerbarg and Richard P. Brown. Yoga: A breath of relief for Hurricane Katrina refugees. Current Psychiatry Journal 2005;4:55-67.

[5]. KaushikHalder, AbhirupChatterjee et al; Improvement in ventilator function through yogic practices -Al Ameen Journal of Medical Science 2012;5(2):197 $-202$.

[6]. Anjum Sayyed, Jyotsna Patil et al;Study of lipid profile and pulmonary functions in subjects with sudarshankriya yoga- Al Ameen Journal of Medical Science 2010;3(1):42-46.

[7]. A. Vedamurthachar, N. Janakiramaiah et al, Antidepressant efficacy and hormonal effects of SudarshanaKriya Yoga (SKY) in alcohol dependent individuals- Journal of Science of Holistic Living and Its Global Application- 2009.

[8]. Bharshankar et al - The effects of sudarshankriya yoga training on cardiovascular function - Journal of Complementary Medicine - 2003.

[9]. Vivekajyotsna et al - Comprehensive yogic breathing program improves quality of life in patients with diabetes- Indian Journal of Endocrinology Metabolism. 2012 May-Jun; 16(3): 423-428.

[10]. P. Narang et al - the role of Sudarshan Kriya Yoga $-2012$.

[11]. TeresitaCorvera et al - Recognising and reducing risk in heart disease - Journal of American Heart Association - 2008.

[12]. James Sharman et al - Determinants of exercise capacity in type 2 diabetes - Journal of Diabetes Care- 2005.

[13]. Dipak B. Chavhan et al -THE EFFECT OF SUDARSHAN KRIYA AND BHASTRIKA PRANAYAMA ON ENDURANCE CAPACITY IN KHO-KHO PLAYERS - International Multidisciplinary Research Journal - September 2013;6(I).

[14]. Vivekajyotsna et al - Comprehensive yogic breathing program improves quality of life in patients with diabetes- Indian Journal of Endocrinology Metabolism. 2012 May-Jun; 16(3): 423-428.

[15]. Kjellgren A, Bood SA, Axelsson K, Norlander T, Saatcioglu $F$ - Wellness through a comprehensive yogic breathing program - a controlled pilot trial BMC Complementary Alternative Medicine. 2007 Dec 19;7:43.

[16]. Brown RP, Gerbarg PL et al - Sudarshan Kriya yogic breathing in the treatment of stress, anxiety, and depression: part I-neurophysiologic model - Journal of Alternative Complementary Medicine. 2005 Feb; 11(1):189-201.

[17]. B.N.Gangadhar, N.Janakiramaiah, B.Sudarshan, K.T. - Stress-related biochemical effects of sudarshankriya yoga in depressed patients - National Journal of Mental Health and Neurosciences, Oct. 1999.

[18]. Sameer Zope et al- Sudarshan kriya yoga: Breathing for health - International Journal of Yoga. 2013 JanJun; 6(1): 4-10. 
[19].Kulur A.B., Haleagrahara N., Adhikary P., and Jeganathan P.S., . Effect of diaphragmatic breathing on heart rate variability in ischemic heart disease with diabetes, Arquate. Journal of. Cardiology 2009;92(6).

[20]. Kaushik RM., Kaushik R., Mahajan SK., Rajesh V., . Effects of mental relaxation and slow breathing in essential hypertension. Complementary Therapy Medicine Journal . 2006 Jun;14 (2):120-6.

[21]. Whitmore Max. How to Lower Your Heart Rate Naturally With Breathing Exercises,- Journal of Education and Practice - 2013.

[22]. Dr. Labiba Abd El-kader Mohamed 1, Effect of slow deep breathing exercise on blood pressure and heart rate among newly diagnosed patients with essential hypertension- Journal of Education and Practice -2013.

[23]. C.-K. Peng,, Isaac C. Henry et al - Heart rate dynamics during three forms of meditation- International Journal of Cardiology 2004;95:19- 27.

[24]. Daniele Martarelli et al - Diaphragmatic Breathing Reduces Exercise-Induced Oxidative Stress - Journal of Experimental Medicine and Public Health 2009.

[25]. Bernardi L, Gabutti A, Porta C, Spicuzza L. Slow breathing reduces chemoreflex response to hypoxia and hypercapnia, and increases baroreflex sensitivity. Journal of Hypertension 2001;19:2221-9.
[26]. Vidiendal Olsen N, Christensen H, Klausen T et al. Effects of hyperventilation and hypocapnic/ normocapnic hypoxemia on renal function and lithium clearance in humans. Anesthesiology 1998; 89(6):1389-400.

[27]. Telles et al, Autonomic changes during 'OM' meditation, Indian Journal of physiological pharmacology, 1995

[28]. Adhana R., Gupta R., Dvivedi J., \& Ahmad S., . The influence of the 2:1 yogic breathing technique on essential hypertension, Indian Journal PhysiologicalPharmacololy, 2013;57(1): 38-44.

[29]. Mourya M., Mahajan AS., Singh NP., Jain AK. Effect of slow- and fast-breathing exercises on autonomic functions in patients with essential hypertension. Journal of Alternative Complement Medicine. 2009 Jul,15(7):711-7.

[30]. Shakeshaft J., . 6 Breathing Exercises to Relax in 10 Minutes or Less. 2012.

[31]. Kirtigandha Salwe Carter and Robert Carter - Breathbased meditation: A mechanism to restore the physiological and cognitive reserves for optimal human performance -World Journal of Clinical Cases. 2016 Apr 16; 4(4): 99-102.

\footnotetext{
How to cite this article:

Donna Adhav Gaikwad, Rachna Arora, Hutoxi Writer. EFFECT OF SUDARSHAN KRIYA ON FUNCTIONAL CAPACITY, QUALITY OF LIFE AND STRESS LEVELS IN PATIENTS WITH TYPE 2 DIABETES: A PROSPECTIVE EXPERIMENTAL STUDY. Int J Physiother Res 2019;7(3):3047-3054. DOI: 10.16965/ijpr.2019.115
} 